\title{
Ordem de palavras em exclamativas com demonstrativos em Português Europeu
}

\author{
Joana Carvalho, Ana Maria Brito ${ }^{1}$ \\ Faculdade de Letras da Universidade do Porto (FLUP) \\ Centro de Linguística da Universidade do Porto (CLUP)
}

\begin{abstract}
:
This paper focuses on the study of the syntactic position filled by the demonstrative determiner (este, esse, aquele) in nominal wh- exclamative sentences in European Portuguese (EP) like 'Que menina esta!'. We draw on works on Spanish and Catalan (Castroviejo Miró 2006 a,b; Alonso Cortés 1999) and develop a hypothesis capable of explaining why the demonstrative in EP can occupy such a position, which apparently is a post-nominal one. We defend the hypothesis that in this type of exclamative the post-nominal position of the demonstrative is the result of an elliptical predicative clause. In order to understand the position of the demonstrative, we also analyse the structures of wh-exclamatives, of predicative clauses and of degree phrases.
\end{abstract}

Keywords: wh-exclamatives, demonstratives, degree phrase, determiner phrase, predicative sentences, ellipsis.

Palavras-chave: exclamativas-Q, demonstrativos, sintagma grau, sintagma determinante, frases predicativas, elipse.

\section{Introdução}

As exclamativas-Q parciais elípticas e os demonstrativos são objeto de estudo em diversas línguas. A conjugação destes dois fenómenos linguísticos, em línguas como o Português, o Espanhol ou o Malgaxe, revela aspetos relacionados com as propriedades específicas de cada sistema linguístico e, em simultâneo, permite a construção de hipóteses que expliquem a presença do demonstrativo (Dem) nas exclamativas-Q parciais elípticas.

Em Português Europeu (PE) observamos a presença de demonstrativos após o nome $(\mathrm{N})$ em exclamativas parciais elípticas como as que se encontram em (1).

(1) Que menina esta!

1 joanacarvalho21@gmail.com, ambarrosbrito@gmail.com 
Partindo desta construção (1) e de uma análise superficial da sua sintaxe, poderíamos ser levados a pensar que este fenómeno é explicado se o demonstrativo estivesse inserido dentro do sintagma-Q (SQ). No entanto, uma observação mais atenta, através da comparação entre a sintaxe das exclamativas frásicas e das exclamativas-Q parciais elípticas com demonstrativo posposto a $\mathrm{N}$, em PE e em outras línguas, revela uma outra hipótese. De facto, em PE, os determinantes, quer sejam demonstrativos, codificando os traços [+def] e [+deítico], quer sejam artigos definidos, com o traço [+def], ocupam a posição mais elevada dentro de um Sintagma Determinante (SDet), mas em (1) a palavra-Q, que, encontra-se na posição mais elevada da exclamativa-Q; por seu lado, o N, menina, ocupa uma posição intermédia. Isto significa que o demonstrativo e a palavra-Q pertencem a sintagmas diferentes. A construção de uma hipótese que determine a posição ocupada pelo demonstrativo dentro da frase exclamativa-Q parcial elíptica será o objetivo deste artigo.

O objeto de estudo deste artigo são as exclamativas-Q parciais elípticas com demonstrativo posposto a $\mathrm{N}$, como em (1) e (2). Contudo, para fundamentar a nossa hipótese vamos também estudar a ocorrência de demonstrativo em PE antes de $\mathrm{N}$ em construções como (3) e nas exclamativas-Q em que o Dem se encontra ausente, como em (4) e (5).

(2) Que linda menina esta!

(3) Que linda esta menina!

(4) Que menina!

(5) Que menina tão linda!

A hipótese a seguir delineada assentará no quadro teórico proposto por Chomsky (1995), o Programa Minimalista, tendo como base a abordagem que Castroviejo Miró (2006 a) faz para o tratamento das exclamativas-Q. A perspetiva cartográfica de Rizzi (1997), e.o., não será abordada para o estudo da periferia esquerda da frase.

O trabalho encontra-se organizado da seguinte maneira: depois da introdução (1.), no ponto 2. analisa-se as exclamativas Q frásicas e em 3. as exclamativas com demonstrativos pospostos; em 4. apresenta-se alguns dados do Malgaxe, uma língua em que o demonstrativo tem vários valores, incluindo o avaliativo, e volta-se às exclamativas nominais com demonstrativos; em 5., apresenta-se breves conclusões e no final as referências bibliográficas. 


\section{Análise sintática de exclamativas-Q frásicas}

A sintaxe das exclamativas-Q frásicas permite-nos delinear uma análise sintática mais precisa das exclamativas-Q nominais elípticas com demonstrativo, por várias razões. Desde logo, as exclamativas-Q nominais elípticas com demonstrativo implicam a elisão de alguns elementos da frase, por isso, precisamos de compreender a sintaxe das exclamativas-Q frásicas, onde todos os constituintes são visíveis e não foram alvo de elipse. Por outro lado, ao defendermos que as exclamativas-Q em análise efetuam uma operação de Movimento-Q, temos de mostrar não só as motivações para a ocorrência deste movimento, mas também localizar a origem do movimento dentro da estrutura sintática, comparando o PE com outras línguas.

Verifica-se que tanto em Português como em Espanhol e Catalão as exclamativas frásicas podem ter um que, realizado ou não, a seguir ao sintagma exclamativo-Q (6 a 8). A possibilidade da presença do complementador que revela a existência de uma projeção de SComp.

(6) (a) Que filme interessante que eu vi no avião!

(b) Que filme interessante eu vi no avião!

(7) (a) Quina pellícula tan entretinguda que vam veure a l'avió! (Catalão, Castroviejo Miró 2006a: 40)

que filme tão divertido que vou ver no avião

'Que filme tão divertido vou ver no avião!'

(b) Que entretinguda que va ser la pellícula! (Catalão, Castroviejo Miró 2006:40)

que divertido que vai ser o filme

'Que divertido vai ser o filme!'

(8) ¡Qué guapa que está Marta! (Espanhol, Eunjung2013:160)

que bonita está Marta

'Que bonita está a Marta!'

Podemos então propor desde já que nas exclamativas-Q opera, à semelhança das interrogativas, um movimento-Q de uma posição mais baixa para uma posição superior localizada na periferia esquerda da frase (Duarte 2003a: 465/6; Castroviejo Miró 2006a:40, Teixeira 2014), operação que descrevemos, em linhas gerais, para (6a), (7a) e (7b) em (9): 
(9)

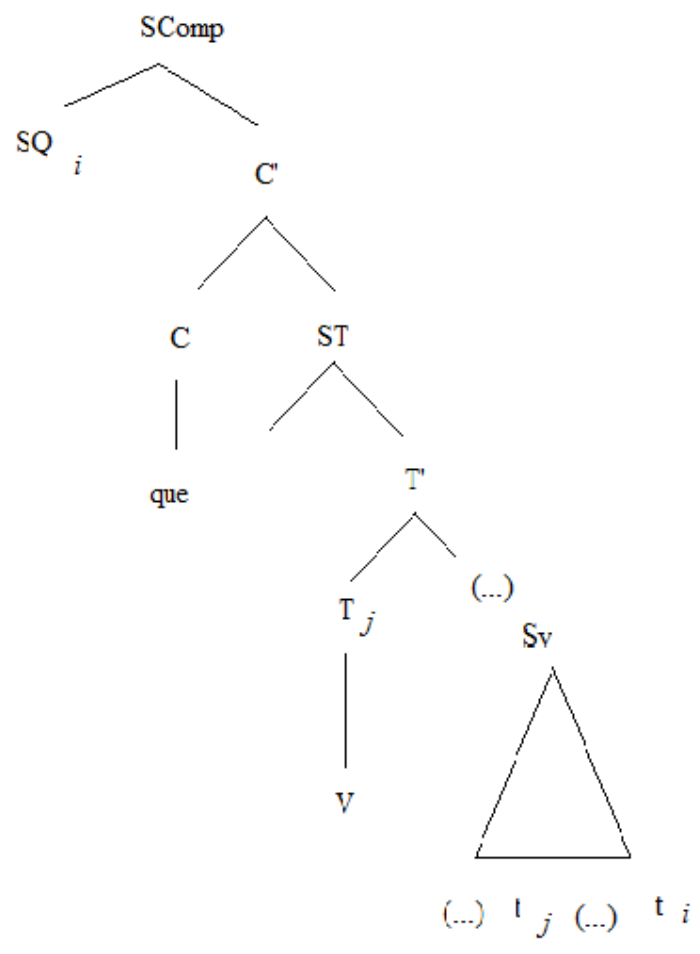

No caso de (6a), (7a) e (7b) o núcleo de SCOMP está preenchido pelo complementador que; em (6b) a posição do complementador está não preenchida (Duarte 2003: 465/6). Por sua vez, o movimento do sintagma-Q (SQ) para a periferia esquerda da frase deve-se a uma necessidade de verificar o(s) traço(s) [+Grau], [+ avaliativo] e [+Q], que se encontra(m) no núcleo de SComp (Guttierrez-Rexach e Andueza 2011:288/9; Castroviejo Miró 2006a:47; Castroviejo Miró 2006b:135/6).

Note-se, no entanto, que pode haver alternativas à análise esboçada em (9). Em alguns exemplos estamos perante exclamativas que contêm adjetivos graduáveis e em que a exclamativa é sempre uma forma de avaliar o alto grau de uma propriedade (Guttiérrez-Rexach e Andueza 2011:289; Hernanz 2001:95). Por essa razão, Castroviejo Miró (2006a), para o Catalão, propõe que, quando temos um exemplo como (7b), aqui repetido como (10), se projeta um Sintagma Grau (SGrau), (11) e (12), e que a palavra-Q, que, a anteceder o ADJ, é um Det /núcleo de Grau, como se descreve em (13):

(10) [sGrauQue entretinguda] que va ser la pellícula. 
(11) [sGrauQue corajosa] que és!

(12) [sGrauQue divertida]!

(13)

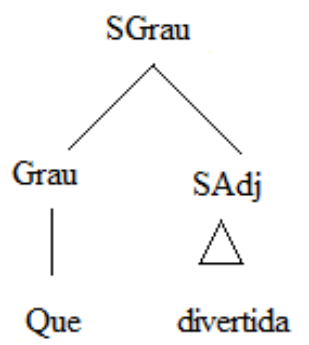

A categoria SGrau foi pela primeira vez proposta por Abney (1987) para as construções que contêm expressões comparativas e consecutivas. Nesta hipótese, o SADJ seria selecionado funcionalmente pela categoria Grau, preenchida por um operador de grau (em Português mais, tão) ou por uma palavra- $Q$ (cf. Castroviejo Miró 2006a:78; Castroviejo Miró 2006b:135/6; Gutiérrez-Rexach e Andueza 2011: 288/9, entre outros). De acordo com os mesmos autores, o SGrau é necessário nas exclamativas-Q porque se está a predicar uma propriedade ou qualidade excecional de uma entidade que ultrapassa aquilo que seria considerado normal dentro de uma escala padrão.

Em certos casos, o operador de grau e o adjetivo graduável não são realizados, visto que podem ser recuperados pelos interlocutores a partir do contexto de enunciação. Assim sendo, justifica-se propor que as exclamativas em (14), que têm leituras paralelas a (15), tenham um SGrau não realizado (Castroviejo Miró 2006a:77; Gutierrez-Rexach e Andueza 2011:290).

(14) (a) Que homem!

(b) Que vestido!

(15) (a) Que homem tão/incrivelmente bonito/ inteligente/ estúpido!

(b) Que vestido tão bonito/ caro!

A propósito deste tipo de exemplos, Castroviejo Miró (2006 a:77/8) afirma tratar-se de um SDet, que contém um SGrau, movido para uma posição mais elevada, chegando a propor a estrutura (16) para o exemplo (7a) :

(16) [SDET Quina pellícula tan entretinguda] que vam veure a l'avió. (Catalão, Castroviejo Miró 2006a: 40) 


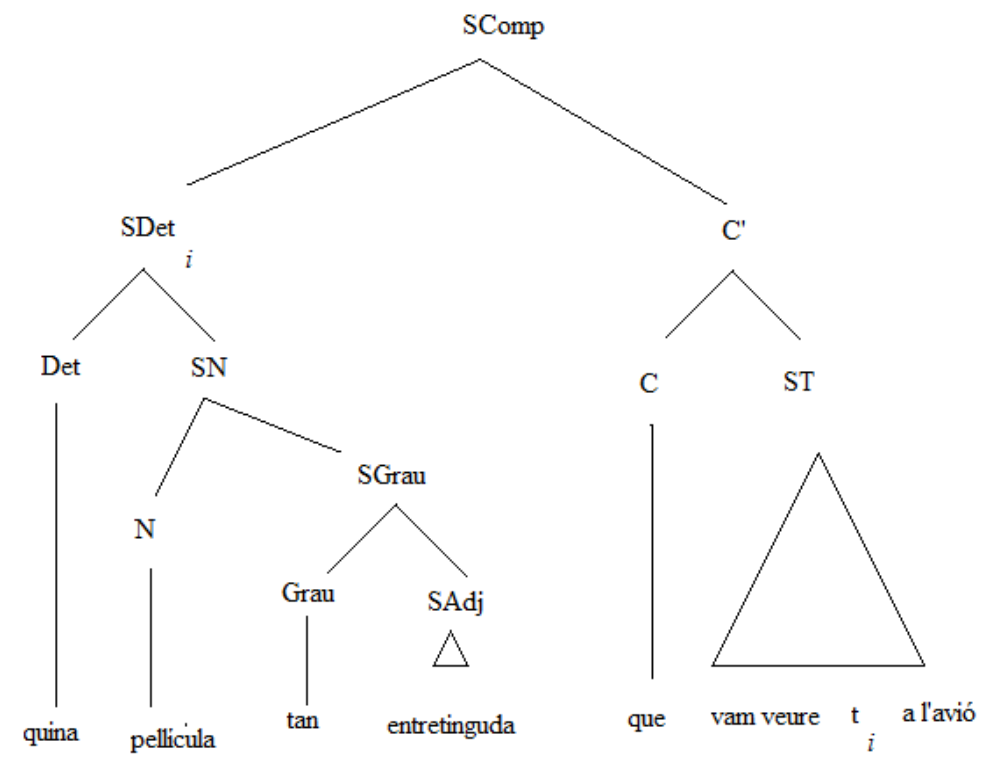

Como dissemos, a análise detalhada de todas estas formas de exclamativas está fora do âmbito deste artigo. Por isso, vamos dedicar a nossa atenção às exclamativas-Q com demonstrativo posposto.

\section{Exclamativas-Q com demonstrativos pospostos}

O Espanhol e o PE possuem exclamativas-Q elípticas com Dem pós-nominal. Por isso, exploramos a seguir as propostas que têm sido apresentadas para explicar este fenómeno nestas línguas.

De acordo com Eguren (1999: 954/5), em Espanhol os demonstrativos em construções exclamativas como as que se encontram em (17) não são verdadeiros demonstrativos pósnominais.

(17) ¡Pobres niños esos a los que dejan ir solos a la muerte!

pobres crianças essas a os que deixam ir sozinhos à morte

'Pobres crianças deixadas sozinhas à morte!'

O autor propõe que em exemplos como os de (17) estamos perante um verbo copulativo implícito e, por esta razão, o demonstrativo funciona como um determinante de um $\mathrm{N}$ elidido, 
como descrito em (18).

(18) ¡Pobres niños (son) esos (niños) a los que dejan ir solos a la muerte!

Alonso-Cortés (1999: 4010) faz uma análise do mesmo tipo para as chamadas exclamativasQ elípticas em Espanhol, como em (19) a (22).

(19) ¡Qué vida la suya!

(20) ¡Qué voz la de Caruso!

(21) ¡Qué casa esta!

(22) ¡Qué tontos ellos!

Para o autor, estamos perante exclamativas-Q em que uma das partes funciona como predicado de uma relação predicativa, dado que, após a palavra qué, se segue uma expressão nominal que contém um elemento linguístico que tanto pode ser um determinante definido seguido de possessivo (19) ou de um complemento em de (20), ou demonstrativo (21) ou mesmo um pronome (22); em qualquer dos casos, há concordância em género e número com o $\mathrm{N}$ que o antecede. $\mathrm{O}$ verbo elidido é o verbo ser, que é recuperado a partir do contexto.

Para o PE, Miguel e Raposo (2013:872/3), ao analisarem o demonstrativo em português, também avançam uma hipótese de tratamento sintático para as exclamativas-Q com demonstrativo pós-nominal na linha da dos autores acima referidos.

Atente-se nos exemplos (23) a (26):

(23) Que vida esta!

(24) Belos tempos aqueles!

(25) Decisão difícil esta!

(26) Que mau feitio esse que tu tens!

Quando estamos perante frases exclamativas semelhantes às que estão em (23) a (26), os autores consideram que há uma oração copulativa com o verbo elidido (27 a 30).

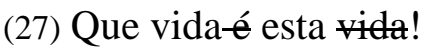

(28) Belos tempos eram aqueles tempes!

(29) Decisão difícil é esta decisão!

(30) Que mau feitio-é esse feitio que tu tens!

Como se pode ver pelos exemplos (27-30), para além da elipse do V copulativo, o $\mathrm{N}$ que 
sucede o demonstrativo foi elidido, originando uma aparente posição pós-nominal do demonstrativo, tal como em Espanhol.

Antes de voltarmos aos exemplos com demonstrativos pospostos, vamos seguir algumas destas sugestões e vamos propor que tanto nas exclamativas-Q elípticas como nas exclamativas frásicas com verbo ser, estamos em presença de uma oração pequena.

Este seria o caso de uma frase como (7b), aqui repetida como (31) (Castroviejo Miró 2006a:65).

(31) [ sGrau Que entretinguda] que va ser la pellícula!

Concordando com Castroviejo Miró (2006a:65) e Alonso Cortés (1999:4010), a estrutura de (31) seria como a descrita em (32), em que há uma oração pequena (equivalente a SGrau), contendo no seu interior um SDet, la pellícula, cuja função sintática é a de sujeito e um SGrau que exerce a função de predicado, estabelecendo-se entre ambos uma relação de predicação (cf. para o Inglês Stowell 1983 e para o Português Duarte 2003b, entre outros) ${ }^{2}$.

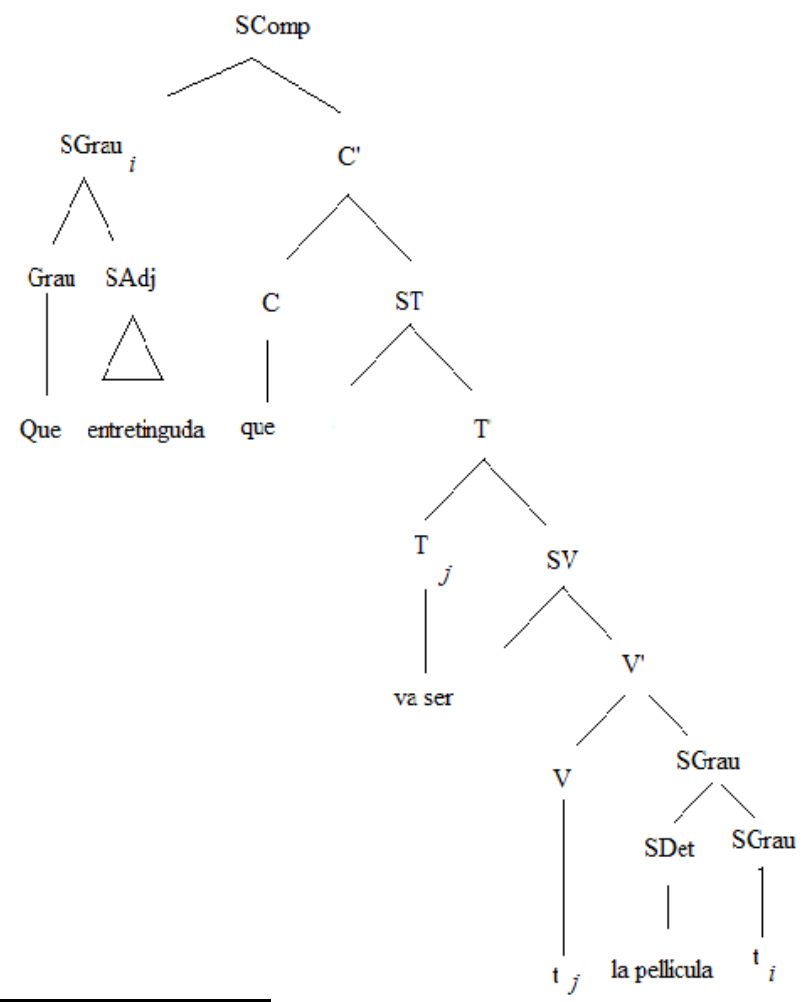

2 Para simplificar ignoramos a presença do auxiliar ir em va ser. 
Em (32) descreve-se o movimento do V para o núcleo de ST, verificando os traços de tempo

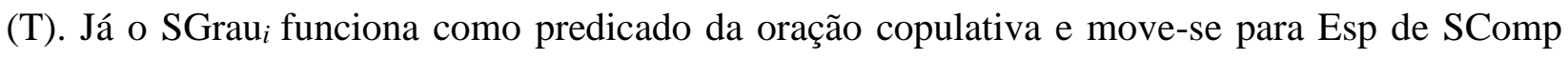
para fazer a verificação dos traços [+Grau], [+avaliativo] e [+Q] presentes no núcleo de SComp.

A presença do complementador que ou dos seus traços, [+Q] e [+avaliativo], no núcleo de SComp despoleta o movimento do sintagma-Q para a posição de Esp de SComp e impede que outros constituintes possam ocupar esta posição.

Vejamos agora o que acontece em frases exclamativas-Q nominais, assim denominadas porque nelas não ocorre qualquer verbo (Hernanz e Suñer 1999:2529).

(33) (=19) ¡Qué vida la suya! (Alvarez 1999: 4010)

'Que vida a sua!'

(34) ¡Qué guapo, tu hijo! (Hernanz e Suñer 1999:2536)

'Que lindo, o teu filho!'

Nestes exemplos, e tal como é defendido por Castroviejo Miró (2006a:65/6), Alonso-Cortés (1999:4010), entre outros, o sintagma-Q, constituído por SDet $(Q u e+S N)$ (33) ou por SGrau (Que+ SAdj) (34), funciona como o predicado das orações pequenas em que se encontra. Os elementos em itálico de (33) e (34) desempenham a função de sujeito da oração pequena com verbo elidido e são, em ambos os casos, SDets definidos.

Recorde-se que, segundo Stowell (1983) e Duarte (2003b:541), uma oração pequena adjetival, como (35), tem uma estrutura como em (36):

(35) A Maria é simpática.

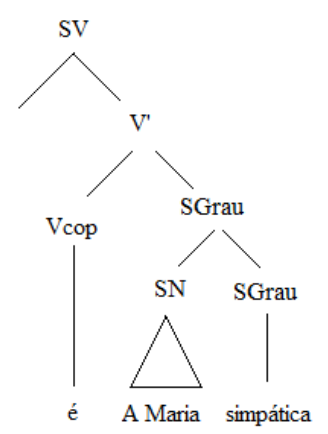


Para adquirir o caso nominativo, o sujeito da oração pequena, A Maria, move-se para a posição de Esp de ST e torna-se o sujeito da frase, e o SV(é) simpática torna-se o predicado da frase (Duarte 2003b:543).

Esta perspetiva pode ser adotada para as exclamativas como (37a): o SDet com o demonstrativo, sendo o sujeito da oração pequena, vai ser o sujeito da frase, através do movimento para especificador de ST. O SGrau funciona como seu predicado, veja-se (37b).

(a) Esta menina é tão linda!

(b)

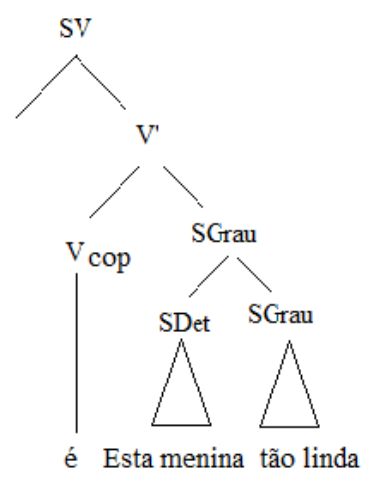

Após estas considerações, voltemos a nossa atenção para as exclamativas com demonstrativos pospostos, como (37) a (39) e compare-se com (40).

(37) Que vida esta!

(38) Que menina esta!

(39) Que menina linda esta!

(40) Que linda esta menina!

Repare-se que os exemplos apresentados de (37) a (40) podem ser comparados com frases exclamativas predicativas com complementador que realizado ou não (41 a 43).

(41) Que vida (que) é esta vida!

(42) Que menina (que) é esta menina!

(43) Que linda (que) é esta menina!

Assim, defendemos que, tanto em (37) a (40) como em (41) a (43), o sintagma-Q é o predicado da oração pequena e o SDet com demonstrativo e $\mathrm{N}$ elidido ou explícito é o sujeito da frase. 
A estrutura sintática dos exemplos como (37) a (40) será, pois, a descrita em (44)

(44)

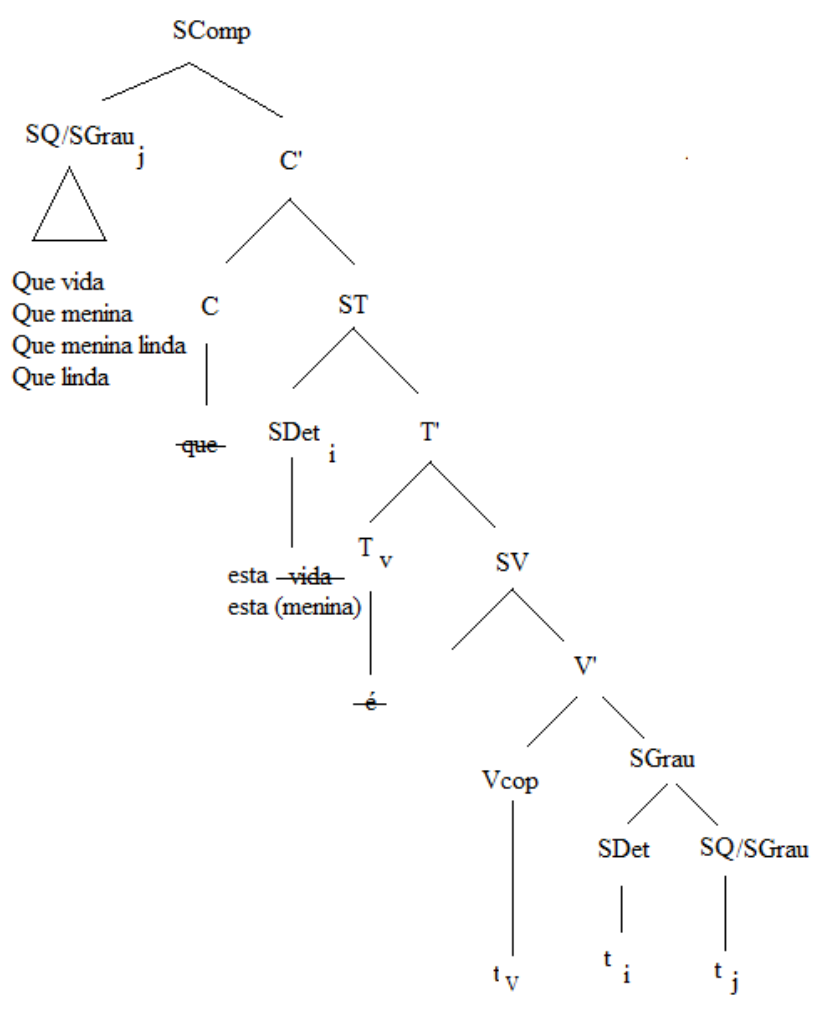

Como (44) evidencia, o demonstrativo não pertence ao constituinte movido para especificador de SComp pelo facto de comportar os traços [+definido] e [+deítico], funcionando como um impedimento para fazer parte do SQ (SGrau ou SDet) movido para uma posição alta. Por seu lado, o verbo copulativo pode ser apagado, dado que o tempo de enunciação é facilmente determinado através do contexto em que se encontram os interlocutores, neste caso o tempo presente.

Quanto à estrutura de (41), Que linda esta menina! a principal diferença reside no facto de o sujeito da oração pequena ter o $\mathrm{N}$ explicíto.

Até este ponto, vimos que o SQ/SGrau tem a função de predicado numa frase exclamativa-Q nominal quando combinado com um SDet definido. Ficou por explorar a relação sintática que se estabelece entre o $\mathrm{N}$ e o SQ/SGrau em exclamativas como (45) a (47):

(45) Que menina tão linda! 
(46) Que noite tão agitada!

(47) Que rapaz alto!

Há testes sintáticos que mostram que, neste caso, o SGrau não é o predicado de uma oração predicativa elíptica, desempenhando antes a função sintática de modificador de $\mathrm{N}$ (Castroviejo Miró 2006a: 67/9). Desde logo, se tentarmos reconstruir este tipo de frase inserindo um verbo copulativo, o resultado não é gramatical.

(48) *Que menina é (tão) linda!

(49) *Que rapaz é alto!

Além disso, nas exclamativas-Q do tipo (45) a (47) podem ocorrer adjetivos que são predicados de estádio (50) ou de indivíduo (51), desde que sejam graduáveis, ao passo que nas orações sem verbo apenas podem ocorrer adjetivos que são predicados de indivíduo (52a), sendo agramaticais predicados de estádio (52b) (Castroviejo Miró 2006a: 67/9). Repare-se que se o adjetivo for de indivíduo, como em (51), a ordem entre SDet e o modificador pode ser alterada, como em 52(a). No caso de ser predicado de estádio a alteração da ordem das palavras resulta agramatical (52b). Esta diferença de comportamento indicia que tanto em (45) a (47), como em (50) a (52a) não estamos perante estruturas predicativas elípticas, mas frente a estruturas exclamativas com modificador.

(50) Que copos limpos!

(51) Que menina modesta!

(52) (a) Modesta, a menina!

(b) *Limpos, os copos!

Repare-se ainda que neste tipo de exclamativas ( $Q u e+N$ ou $Q u e+N+S G r a u)$, ao contrário de frases predicativas (53) ou de predicação secundária (54), não se pode inserir nenhum artigo definido ou demonstrativo (55) ou substituir o $\mathrm{N}$ comum por um $\mathrm{N}$ próprio, (56) e (57). ${ }^{3}$

(53) A menina é alta!

(54) (a) Considero a menina alta!

(b) Considero a Maria linda!

${ }^{3}$ As exclamativas (56) e (57) resultariam gramaticais se, no contexto de enunciação, estivesse presente mais do que um indivíduo com o nome Maria, mas nesse caso o nome próprio Maria teria sido recategorizado como nome comum. 
(55) *Que a/esta menina!

(56) *Que Maria tão linda!

(57) *Que Maria!

Tais dados indiciam, mais uma vez, que pode haver exclamativas nominais que não tenham uma origem predicativa.

\section{As exclamativas em Malgaxe e em PE com Dem + N}

Neste ponto iremos mostrar, através de exemplos do Malgaxe, uma língua da família austronésia, falada em Madagáscar, que o demonstrativo pode funcionar como introdutor de exclamativa elíptica, reunindo valores de graduação e de avaliação, valores que em Português e noutras línguas costumam estar associados aos morfemas Q.

Com efeito, o Malgaxe utiliza como estratégia de construção de exclamativa o demonstrativo izany seguido de um sintagma que pode ser um SV (58), um SN (59) ou um SPrep (60) (Potsdam 2011:662).

DEM beberPassiva DET Paulo

'O que/ Como o Paulo bebeu!'

(59) Izany ngidi-n' ireo voankazo ireo!

DEM amarguraLIGAÇÃO DEM fruta DEM

'Que amargo que o fruto é!'

(60) izany ao ambanin' ny fandriana!

DEM Locativo debaixo da cama

'As coisas debaixo da cama!'

No sistema de demonstrativos da língua Malgaxe, izany é o demonstrativo que indica que o referente se encontra a uma distância indefinida/ indeterminada em relação ao locutor e não tem marcas de flexão de género ou de número. 
Potsdam (2011:678/680) afirma que o determinante izany e a sua sintaxe permitem que a frase adquira um sentido exclamativo, isto é, « (...) o morfema exclamativo está associado ao determinante».

$\mathrm{Na}$ visão do autor, as exclamativas do Malgaxe não têm uma estrutura frásica mas uma estrutura nominal, constituindo-se como um SDet (61).

(61) $[$ sDet [Det izany] [sotrohiny] SN]

\section{DEM beberPassiva3SG}

'A quantidade/ As coisas bebidas por ele!'

Um dos argumentos que o autor utiliza para apoiar a sua hipótese prende-se com a ordem dos constituintes nas frases exclamativas. A ordem de palavras não marcada é de predicado inicial e sujeito final (V O S), sem verbo copulativo (62). No entanto, nas frases exclamativas esta ordem inverte-se e passamos a ter uma ordem marcada de sujeito inicial, como se vê em (61).

(62) Miasa ny zazalahy

trabalhar o rapaz

'Os rapazes estão a trabalhar'.

Um outro argumento para justificar o tratamento das frases exclamativas em Malgaxe como nominais e não como frásicas está ligado ao facto de o demonstrativo izany não se comportar como um sujeito, mas como um determinante dentro de um SN (63), dado que não pode coocorrer com partículas de tópico ou de foco (64).

(63) Izany (ronono) nosotrohiny!

DEM (leite) PASSADObeberPASS.3SG

'A quantidade (de leite) que ele bebeu!'

(64) *Izany (ronono) dia/no nosotrohiny!

DEM (leite) tópico/foco PASSADObeberPASS.3SG

Nas exclamativas nominais típicas nesta língua temos um determinante seguido de um SN (65) a (68). Apenas o demonstrativo izany pode anteceder N nestes contextos e afeta todo o SN.

(65) izany trano!

Dem casa 
'Que casa!'

$\begin{array}{rrrrr}\text { (66) Izany } & \text { ahaingan' } & \text { ny } & \text { f-amakia-ny } & \text { boky! } \\ \text { Dem } & \text { rapidez } & \text { o } & \text { NMLZ-ler-3sg } & \text { livro }\end{array}$

'Que rápido que ela lê!'

(67) Izany ditran' ny alika!

Dem teimosia o cão

A teimosia do cão!'

(68) *Izany ilay/ny trano!

Dem aquela/a casa

'Que casa!'

O Malgaxe mostra assim que o demonstrativo izany funciona como um elemento que introduz uma exclamativa e que assume diferentes valores, incluindo aqueles que se associam a um elemento-Q: exclamativo, determinante, adjetivo quantificador e grau. Isto revela que nas línguas existe pelo menos um elemento linguístico que é selecionado para introduzir uma frase exclamativa. Trata-se de um elemento que em parte, ou na sua totalidade, foi destituído dos seus valores marcados na gramática da língua a que pertence. Parece-nos que o valor comum em todas as línguas atribuído a esses elementos linguísticos é o valor exclamativo / avaliativo, sobretudo nos contextos em que há uma interpretação de grau.

Em PE também existem exclamativas marcadas unicamente pela presença de demonstrativo seguido de N (69) a (71), formando com este um SDet (Duarte 2003a:482; Carvalho 2010:85). Repare-se que o Dem ocupa aqui, indiscutivelmente, a posição mais elevada dentro do SDet.

(69) Aquela menina!

(70) Esta vida!

(71) Esse rapaz!

Tanto Cunha e Cintra (1984:336), como Wolf (1982:165), a propósito deste tipo de exemplos, defendem que em PE o demonstrativo expressa valores afetivos, sendo plausível a existência de um traço [+avaliativo] que é dado pela presença do demonstrativo, aliada a uma prosódia de exclamação. 
Deste modo, o demonstrativo nestes enunciados tem não só uma interpretação deítica, referencial e definida (Carvalho 2010:95), como também avaliativa.

Pelo contrário, nas exclamativas que analisámos neste texto, em especial em exemplos como (1), (2) e (3), em que surge um demonstrativo numa posição baixa, não estamos perante SDets mas sim orações predicativas elípticas. Nestas circunstâncias, o demonstrativo não se eleva para Esp de SComp porque esta posição já está ocupada pelo SQ. De facto, para se tornar visível em FF, o SQ tem de se elevar para a posição de Esp de SComp para verificar o traço [+Grau], [ + avaliativo] e [+Q] presente nas exclamativas-Q, impedindo, assim, a elevação do Dem.

\section{Conclusões}

Neste texto apresentámos uma hipótese explicativa para a presença do demonstrativo pósnominal em exclamativas-Q nominais elípticas (Que menina esta!), partindo da sintaxe das exclamativas-Q frásicas e da comparação com outras línguas com o mesmo tipo de construção.

Defendemos a hipótese de que nas exclamativas-Q nominais a posição do demonstrativo, após o sintagma-Q, resulta do facto de estarmos perante frases predicativas elípticas.

Esta hipótese foi avançada para o Espanhol e o Catalão por Castroviejo Miró (2006 a, b), Eguren (1999) e Alonso-Cortés (1999) e para o PE por Miguel e Raposo (2013).

Os principais argumentos a favor desta hipótese foram o paralelismo com exclamativas frásicas com verbo copulativo explícito; o paralelismo com exclamativas com que explícito em $\mathrm{C}$ e o facto de em Português não haver facilmente demonstrativos pospostos em SDets, fora do tipo de exclamativas aqui estudado.

Na nossa análise, recorremos à hipótese de que a cópula seleciona uma oração pequena (Stowell 1983, Duarte 2003b). Na oração pequena o Dem está dentro de um SDet sujeito, que se move para a posição de especificador de ST para verificar o caso nominativo. Por seu lado, o sintagma-Q / SGrau é o predicado da oração pequena e move-se para a posição de especificador de SComp, atraído pelo complementador que e pela presença dos traços [+Q] [+avaliativo] em Comp. 
A hipótese de frase predicativa elíptica não se aplica, no entanto, a construções exclamativas do tipo Que menina tão linda! ou Esta menina!, que mostrámos terem uma estrutura SDet, acompanhado ou não de um modificador adjetival.

De forma a compreender melhor este tipo de construção e os seus valores, confrontámo-las com exclamativas idênticas em Malgaxe. Como foi possível observar a partir dos exemplos fornecidos por Postdam (2011), o demonstrativo izany é o introdutor de frases exclamativas nominais e apresenta valores típicos de uma palavra-Q em construções de Grau: determinante, quantificador e expressão de grau. Contudo, o aspeto mais importante associado aos valores do Dem em Malgaxe é o facto de o Dem possuir um valor exclamativo, resultante das particularidades sintáticas que possui nesta língua. Também em PE, tal como mostraram Cunha e Cintra (1984) e Wolf (1982), o Dem possui um valor [+avaliativo] / [+exclamativo] quando introduz uma exclamativa nominal.

Vimos que o Dem pós-nominal nas exclamativas-Q elípticas tem os valores que tipicamente se associam ao sistema dos demonstrativos em PE: [+deítico], [+referencial] e [+definido] (Carvalho 2010). Consequentemente, o Dem não se encontra em posição pós-nominal neste tipo de exclamativas mas faz parte de um SDet sujeito de uma oração predicativa elíptica.

\section{Referências Bibliográficas}

Abney, Steven, (1987) The English Noun Phrase in its Sentential Aspect. PhD. Dissertation, MIT.

Alonso-Cortés, Angel (1999) Las construcciones exclamativas. La interjéccion y las expressiones vocativos. In Bosque, Ignacio \& Demonte, Violeta. (eds) Gramática descriptiva de la lengua española. Madrid: Espasa, Vol.3, pp. 3993-4050.

Carvalho, Joana (2010) A Posição do Demonstrativo em Português Europeu. Dissertação de Mestrado. Faculdade de Letras da Universidade do Porto.

Castroviejo Miró, Helena (2006a) Wh- exclamatives in Catalan, PhD Dissertation, U. Barcelona. 
Castroviejo Miró, Helena (2006b) A degree-based account of wh- exclamatives in Catalan. In Estela Puig-Waldmüller (ed.) Proceedings of Sinn und Bedeutung 11, Barcelona: Universitat Pompeu Fabra, pp.134-149

Chomsky, Noam (1995) The Minimalist Program, MIT Press, Cambridge, Mass.

Cunha, Celso \& Cintra, Lindley (1984) Gramática do Português Contemporâneo. Lisboa: Edições Sá da Costa (17 edição).

Duarte, Inês (2003a) Frases exclamativas. In Mateus, Maria Helena et al. (2003) Gramática da Língua Portuguesa. Lisboa: Caminho (7ª edição), pp.479-487.

Duarte, Inês (2003b) A família das construções inacusativas. In Mateus, Maria Helena et al. (2003), Gramática da Língua Portuguesa. Lisboa: Caminho (7ªedição), pp.507-548.

Eguren, Luís Javier (1999) Pronombres e Advérbios Demostrativos. Las Relaciones Deícticas, in Bosque, Ignacio \& Demonte, Violeta (eds), Gramática Descriptiva de la Lengua Española, Madrid: Espasa, vol. I, pp. 929-972.

Eunjung, You (2013) La partícula enfática que en las oraciones exclamativas: el análisis sintáctico en el marco teórico minimista. Argos, Caracas, v. 30, n. 59, p. 159-183.

Gutiérrez-Rexach, Javier \& Andueza, Patrícia (2011) Degree Restrictions in Spanish exclamatives. In Luis Ortiz-López (ed.) Selected Proceedings of the 13th Hispanic Linguistics Symposium, Sommerville, MA: Cascadilla Proceedings Project, pp. 286-295.

Hernanz, Maria Lluïsa (2001) ¡En bonito lío me he metido! Notas sobre la afectividad en español. Moenia 7. Santiago de Compostela: Universidade de Santiago de Compostela, Servicio de publicacións, pp. 93-109.

Hernanz, Maria Lluïsa \& Suñer, Avellina (1999) La predicación no copulativa. Las construcciones absolutas. In Bosque, Ignacio \& Demonte Violeta. (eds.) Gramática descriptiva de la lengua española, Madrid: Espasa, vol. 2, pp. 2525-2560.

Miguel, Matilde \& Raposo, Eduardo Paiva (2013) Determinantes. In Raposo, Eduardo Paiva et al. (2013) (eds.) Gramática do Português, Lisboa: Fundação Calouste Gulbenkian, volume I, pp. $817-879$. 
Potsdam, Eric (2011) Expressing exclamatives in Malagasy. In Yap, Foong.; Karen GrunowHårsta \& Janick Wrona (eds.), Nominalization in Asian Languages: Diachronic and typological perspectives. Amsterdam/Philadelphia: John Benjamins, pp. 659-683.

Raposo, Eduardo Paiva; Nascimento, Maria Fernanda Bacelar; Mota, Maria Antónia Coelho; Segura, Luísa; Mendes, Amália (2013) Gramática do Português. Lisboa: Fundação Calouste Gulbenkian.

Rett, Jessica (2008) A degree account of exclamatives. In Tova Friedman \& Satoshi Ito (eds.), SALT XVIII, Ithaca, NY: Cornell University, pp. 601-618.

Rizzi, Luigi (1997). The fine structure of the left periphery. In Lillian Haegeman (ed.), Elements of grammar, Dordrecht: Kluwer, pp.281-337.

Stowell, Tim (1983) Subjects Across Categories, The Linguistic Review 2, 285-312.

Teixeira, Joana (2014). Alguns aspetos sintáticos e semânticos das exclamativas $Q$ frásicas em $P E$, Dissertação de Mestrado em Linguística, Faculdade de Letras da Universidade do Porto. Wolf, Elena Maria (1982) O Demonstrativo no Texto, Boletim de Filologia, XXVII, 1-4, Instituto Nacional de Investigação Científica - Centro de Linguística da Universidade de Lisboa, Lisboa, pp. 155-176. 